\title{
Self-Assessment in Second Language Teaching: Journals
}

\author{
María José Martínez Azorín \\ Universidad de Alicante
}

\begin{abstract}
This paper stresses the importance of self-evaluation in the second language class today, and in particular, the advantages of having students keep a regular journal. Taking the methodological framework offered by the Communicative Approach to Language Teaching as a starting point, this essay discusses the dynamic interdependance of purpose, methodology and evaluation within the curriculum. In this sense, formative or ongoing evaluation becomes one of the most practical assessment techniques for controlling our students' progress as well as the effectiveness of our teaching program. Self-evaluation has a number of additional advantages related both to the affective implication of students in introspecting about their learning processes and to students' participation in class management. The essay goes on to discuss the characteristics of a particular self-assessment technique: journals.
\end{abstract}

\section{Introduction}

If we had to define the present situation as far as second language teaching and learning is concerned, we could start by saying that today there is a clear awareness of the need to give equal attention both to language form, as has traditionally been the case, and to language use. In this sense, language learning is conceived as the process of mastering a set of social conventions governing language forms and behaviour within a particular sociocultural group in order to be able to negotiate meaning by means of them. In other words, in our teaching we try to cater to the development of all aspects of communicative competence and its four major components-grammatical competence, sociolinguistic competence, discourse competence and stiategic competence (Omaggio 7)-thus enabling our students to master the unity of ideational, interpersonal and textual knowledge which will allow them to communicate as members of a given social community.

In this respect, the Communicative Approach to Language Teaching provides us with a teaching curriculum characterized by the dynamic interdependence of its three components-purpose, methodology and evaluation-those being designed to answer three interrelated questions: what is to be learned? how is the learning to be undertaken 
and achieved? to what extent is the former appropriate and the latter effective? (Breen and Candlin 89-90). This paper will focus on the the third question and third component-evaluation-always keeping in mind that the term «third» is simply a result of our analytical and expositive needs. I will try to justify the actual relation of interdependence between evaluation and the other two components within this methodological framework, and I will devote the last part of this paper to journals, an activity that in my opinion responds to the current trends in assessing the effectiveness of our classroom teaching activities.

\section{Evaluation}

Today tests are concerned with evaluating real communication in the second language. Evaluation is not external to the purposes of the curriculum or to the actual process of learning and teaching. Since our judgements on the acceptability of communicative performance are the result of the conventions that we share, negotiate and change, I agree with Breen and Candlin when they state that «evaluation within the curriculum can exploit this 'judging' element of everyday communicative behaviour in the assessment of learners' communication and metacommunication. The highly evaluative aspect of communication can be adopted as the evaluation procedure of the curriculum» (105 emphasis is mine).

On the other hand, if that «judging» element of everyday communication is the basis of the learners' progress, evaluation-of oneself, of others and of oneself by others-is obviously an intersubjective question, which means the communicative curriculum relies on shared and negotiated evaluation criteria. This statement raises two consequences which I regard as rather important to my purposes: first, a communicative use of evaluation will stress formative or ongoing evaluation, rather than summative or end-of course evaluation (the emphasis on formative evaluation does not mean a total abandonment of summative evaluation, whose function is to assess the learner's progress in the development of some underlying competence, as we will see below). A negotiated evaluation within the classroom produces formative feedback for the teacher, who may make decisions regarding appropriate modifications in the instructional process, and for students, who can identify areas of strength and weakness and perhaps suggest alternative learning activities (Bachman 83). This fact leads us to the second consequence: formative evaluation within the curriculum also involves an evaluation of the curriculum itself, for it can shape and guide decisions within the curriculum design process:

Evaluation within and of the curriculum can be a powerful and guiding force. Judgements are a crucial part of knowledge, learning and any educational process. By applying judgements to the curriculum itself, evaluation by the users of that curriculum can be brought into the classroom in an immediate and practical sense. Once within the classroom, evaluation can be made to serve as a basis for new directions in the process of teaching and learning. (Breen and Candlin 105)

It follows from these considerations that a communicative curriculum will favour the use of an integrative type of test over a discrete-point one. The former is any test 
that requires a fairly rapid processing of sequences of elements in the language that characterizes normal communication (Oller 486). It will involve more than one of the traditionally recognized four skills-listening, speaking, reading and writing - and the simultaneous use of all the components of the communicative competence we mentioned above. Within this category we could include dictation, cloze procedure, essay writing, oral interviews of various types, role-plays, telling a story, etc.

Nevertheless, Omaggio (309-11) shows her growing concern about a fact that is still frequent: the existence of a widening gulf between our course goals - often stated in communicative terms-and their measurement. Many tests still tend to be discretepoint in nature, that is, that type of test in which, according to behaviouristic languagelearning theories, only one point of grammar, or only one skill is assessed at a time. As defined by Oller, the discrete-point test is «somewhat like a series of well-aimed rifle shots pointing at particular targets» (481). Items are presented in single-sentence frames, out of context. Students do not even have to process the meaning of the individual sentences on the test to do the tasks that are required of them. As Omaggio holds, many students have learned to "short-circuit» grammatical exercises of this type, which gives the impression that «success on language tests involves learning a few grammatical 'tricks' rather than processing language for some authentic purpose» (311). In this sense we can understand the recent creation of American organizations (i.e. the Princeton Review) aimed at preparing students to succeed on the standard exams (TOEFL, GRE, GMAT, and SAT) required by American universities in order to enroll in their programs. Such preparation is based on the fact that these tests are «llenos de trucos, y hay que aprender a combatirlos,» as they are elaborated with «preguntas no aptas para nerviosos, que parecen creadas para calibrar el nivel de agudeza más que para comprobar los conocimientos de inglés» (El País 9, 381, 8). If learning some «tricks» will allow a student to pass a test, we can certainly doubt its effectiveness as a measure of his/her linguistic competence, not to speak of his/her communicative competence.

If we take the learner's point of view, foreign language skills can be assessed along two different lines: (a) by means of examinations or tests, in other words, assessment as an external activity (usually carried out by a teacher or trained examiner), and (b) by means of self-report or self-assessment, that is, assessment seen as an internal or selfdirected activity. We have traditionally been more familiar with the first type of assessment. Yet during the last decade there has been an increasing interest in methods for self-assessment of foreign language proficiency, and several techniques and materials have been developed in this respect, such as progress cards and other record keeping devices, questionnaires, rating scales and check-lists, and, in much more sophisticated environments, videos, audio cassettes and computer-assisted assessment (Oscarson 5-10).

It is my purpose to stress here the advantages of involving learners in evaluating their courses by means of a technique fairly wide-spread in the American university context, for instance, but rarely used in our educational environment. ${ }^{1}$ I mean the use of journals in which students are required to reflect about their learning processes, so that a sort of dialogue can be established with the teacher. Furthermore, students are also encouraged to write about any free topic they are interested in at any particular moment, in an attempt to increase their ability to express communicative thoughts, to promote individual expression. Through this activity, then, we set out to achieve two goals: to assess the progress of our teaching programs, on the one hand, and to control 
the development of our students' underlying communicative competence in the second language, on the other. ${ }^{2}$

This technique, though, is not without several disadvantages. As A. Waters suggests (5-7), the fact that the teacher asks students to judge the course may give the impression of certain lack of competence on the teacher's part. The chance to give their opinions about the way a course can be improved could generate some expectations in the students which may not always be fulfilled, thus creating a feeling of disappointment. Some students, particularly in those contexts characterized by a teachercentered situation, may feel uneasy about «criticizing» the teacher, whereas in other contexts the reverse case, that is, irresponsible criticism out of all proportion, is also possible. Finally, we will always have doubts about the most correct way to interpret such criticism.

Nevertheless, journals also provide us with several positive sides which can compensate for the previous shortcomings. I will try to expose them by defining the different features that characterize journals as an evaluative tool. In order to do so, I will adapt the model proposed by Bachman containing five distinctive features for classifying different types of language tests (97), and I will apply it to journals. These features are: the intended purpose, the content upon which a test is based, the specific technique or method it employs, the frame of reference within which its results are to be interpreted, and the way in which it is scored.

(1) The intended purpose. Any given language test is usually developed with a particular primary use in mind, either for an educational program or for research. In research, language tests can be used to provide information about language teaching and acquisition, or to verify or refute hypotheses about the nature of language proficiency. In educational settings, language tests provide information for making a wide variety of decisions regarding selection, placement, progress, achievement, etc.

We could say that journals have a function in both cases. As was pointed out earlier, in these journals, students are expected to make judgements about the way they face a particular educational program, as well as to write about any free topic they are interested in. The teacher, in his turn, can both judge on the student's individual progress and consequently make modifications, if necessary, in the teaching and learning process. On the other hand, if during the 1970's a great deal of work in Communicative Language Teaching focused on syllabus design, to the detriment of other phases of language programs, nowadays researchers are beginning to examine the links between evaluation and innovation in language-related development programs, and, in this respect, journals can be a valuable source of information. Numa Markee, for instance, describes the use of MATESL students' journals as evaluative tools for the management of language education-related innovation.

(2) Content. The content of language tests can be based on either a theory of language proficiency or a specific content area, generally as provided in a course syllabus. According to Breen and Candlin, in communicative evaluation some criteria for eventual success--in some particular task - can be initially negotiated, and the degrees of success or failure can themselves be further negotiated on the basis of the original criteria. Negotiation on those criteria is, therefore, a matter for communication (105). 
In accordance with the use of journals I have proposed so far, the only negotiated criteria upon which any further negotiation could be based would be precisely the contents and the effects of what students are expected to write about rather than a particular level of achievement based on an instructional unit. (Let us not forget that the successful use of journals depends on clearly stating the purpose of keeping a journal and making sure that students understand the benefits of initiating an honest dialogue with the instructor). This means journals can be regarded as instruments for formative evaluation, in the sense that they inform us about possible problems and appropriate modifications in our teaching process or in the curriculum as a whole. But from the point of view of the abilities we are measuring, they are also a type of summative evaluation, since they can certainly assess the learners' progress in the development of some underlying competence. Nevertheless, if we decide that it is desirable, a rating scale for self-assessment can be negotiated between the teacher and the students, so that the learners can give concrete form to their judgements (this point will be further developed when dealing with scoring procedures).

Another positive consequence derived from having our students write about their own learning process is that, as Waters points out (7), if serious difficulties are identified and students only «evaluate» behind the instructor's back, «an increasingly negative groundswell of frustration and resentment will arise. A system that allows for consultation with all the parties concerned, however, can go at least some of the way toward resolving these conflicts.»

There are some affective considerations involved in this statement which form the basis for our interest in requesting our students to write about any topic they choose. Krashen and Terrell (37-39) see the learner's emotional state or attitude as an adjustable filter that freely passes, impedes or blocks the input necessary for language acquisition. Certain affective variables are related to second language achievement. Learners with a low affective filter receive more input, interact with confidence, and are more receptive to the input they receive, whereas anxious learners have a high affective filter-fear, embarrassment-which prevents acquisition from taking place. In order to lower the affective filter of second language learners, Krashen and Terrell call for the creation of a social community in the classroom, for which the target language is the medium of social exchange: the instructor not only directs but participates in the social interaction, and anyone who wants to participate in the social exchange must do so via the target language.

In my opinion, journals are a more than adequate way of creating this special atmosphere that enhances language learning. ${ }^{3}$ Habitual free entries, accompanied by feedback from the teacher, are a means of communication and a source of information about the personalities and interests of our students. Showing some sound curiosity about them can give our students the comforting - and unfortunately infrequent-impression that they are more than mere numbers to the teacher, who can actually treat them with the tact and psychological insight that sometimes is missing when there is not a more personal relationship involved. ${ }^{4}$ On the other hand, asking our students to introspect about their learning process in their journals can also produce an effect in this respect: if a student raises a problem and it is resolved satisfactorily for both parties, that also lowers the affective filter, which brings us back to the idea that the way a student reacts to class management and to his learning process can also be a part of his interests. 
I would not like to close this point without making reference to another positive aspect derived from involving the learners in course evaluation, and that is that some class management activities certainly imply some kind of «risk.» If the students' suggestions and ideas are also used in class, the responsibility for the success or failure of the activities carried out in class is not for the teacher to bear alone any more: classroom management becomes a «joint endeavour,» one shared by the teacher and the learners, which means students are involved not only from a self-evaluative point of view, but also as far as class management is concerned. This makes Jefferson's famous statement- «tell me and I forget, teach me and I remember, involve me and I learn»-doubiy true.

(3) Testing method. Asking students to express their reactions to the teaching method or to write freely can give the impression that journals are a kind of informal ongoing learner evaluation. Whereas a journal is certainly less «formal» than any type of external assessment, it is also possible to deal with it in a systematic, structured way. As Waters holds, «this is necessary since otherwise there is the likehood that the full range of important, differing issues will not always surface or be given sufficient attention, nor will any subsequent decision-making be conducted in an appropriate manner. In addition, such an approach helps impart a sense of security to everyone concerned, which is very important if participation in this sort of activity is unfamiliar» (10).

On the basis of my experience, it seems to me it is wise to require students to turn in a journal approximately every two weeks, from the very beginning of their second language instruction period. The number and extension of the entries will vary, depending on the level of knowledge (something which also affects the scoring procedure, see below). The teacher will provide feedback on those journals in the form of individual comments in the journal margins (or, if feasible, by means of a tape where the instructor can record full individual responses to all the issues raised by students in their journals, a technique in accordance with the multidimensionality—of media in this case-that characterizes Communicative Language Teaching), and/or a «collective» journal distributed to the class containing a summary of those problems which deserve class discussion, and the solutions proposed. Further follow up activities, such as meetings in office hours, are also encouraged.

If we take into account that one of the goals of Communicative Language Teaching is authenticity - of materials, of tasks-there is no doubt about the fact that the activity I am describing does encourage realistic communication practice, as it is the exchange of views about the reasons and consequences of a number of teaching and learning techniques. Furthermore, in writing course evaluation reactions in English, «learners have an opportunity to use language for a realistic purpose in a normal way, involving a wide range of vocabulary, structures, functions, and so on typical of much educational and professional discourse» (Waters 8).

(4) Frame of reference. The results of language tests can be interpreted in two different ways, depending on the frame of reference adopted. When tests scores are interpreted in relation to the performance of a particular group of individuals, we speak of normreferenced interpretation. If the results are interpreted with respect to a specific level or domain of ability, we speak of a criterion or domain-referenced interpretation. 
The criteria mentioned above clearly apply to external means of assessment, but neither of these two cases is applicable to journals. On the one hand, we are testing a curriculum, the way a particular teaching program is being developed in relation to the students. On the other hand, we are also testing the development of our students' communicative competence. This does not mean we are referring to a particular domain of ability as established in an instructional unit. If this were the case, a great deal of deliberate learning associated with the instructional syllabus-and therefore conscious mastery of native speaker forms - would be expected. Yet in journals we test what has been internalized-or acquired in Krashen's terms-and therefore, we must expect interlanguage (Clark 14). If we have to speak of a frame of reference, it should be the student's previous performance. Since journals are a periodic activity, we can control student progress in communicative competence as they move through the instructional program. In order to do so, we must refer to the students' previous journals.

(5) Scoring procedure. I have already referred to some affective considerations which play an important role in learning. These affective matters are even more decisive in language testing, as E. Shohamy points out: «We know that learning a second or foreign language involves social and psychological factors such as attitude, motivation, self-esteem, and confidence. It is possible that such affective factors are even amplified in second language testing situations» (14). It has been found out that students prefer those tests which, in addition to resembling actual performance in real life, can also be used as learning instruments and create low anxiety by providing a relaxed atmosphere.

I believe the use of journals motivates students for several reasons: (a) there is a real exchange of views between the students and the instructor, (b) students' opinions are taken into account and affect class management, so that they can share the instructional responsibility with the teacher and be aware of their own progress, (c) students write about topics of their own choice, etc. We could almost assure that journal writing provides students with a more than relaxed learning atmosphere. Even if we accept that anxiety can be a negative factor when learning is concerned, we must also recognize Brown's notion of «facilitative anxiety,» by which he means a positive concern-some apprehension-over a task to be accomplished, since «otherwise, a learner might be inclined to be 'wishy-washy,' lacking that facilitative tension that keeps one poised, alert, and just slightly unbalanced to the point that one cannot relax entirely» (106). In other words, scoring the students' journal entries can have a positive effect on their learning process and to such an extent that one feels certainly tempted to believe that scoring is necessary.

Yet, applying a scoring procedure to students journals raises another question: Where does the difference between journals, as presented in this paper, and other external types of assessment-particularly essay writing-lie then? In this sense, we must set up a distinction between real scores and the feedback we provide our students. The former is a grade, the latter can consist of both personal reactions focused on the content of what the student writes about, and error correction, centered on problems of vocabulary, structure and functions. Whereas we can do without a grade, feedback becomes an essential ingredient in this type of self-assessment. Once again, it will correspond both to the teacher and the students to make decisions about the way, if any, in which journals should be scored. It is very likely that journal writing is an activity carried out simultaneously with other external types of assessment, both formative and 
summative, which will account for the students' level of achievement of the domains established in the syllabus and which will probably be scored. If this is the case, we can concentrate on using the journals for the purposes previously stated, that is, making judgements on the educational process and controlling our students' internalized competence in the second language, which we can help to improve by making adequate corrections. In addition to this purpose, some teachers may also wish to use this information as the basis of a grade. If so, a sort of compromise'solution can be suggested: since journals are conceived of as instruments for self-assessment, a rating scale can be negotiated between the instructor and the students-let us not forget the negotiation of this criteria as the basis of further communication in the second language-so that students themselves can evaluate their progress and give it concrete form. ${ }^{5}$

As far as correction is concerned, the teaching methodology we are advocating encourages us to follow a «correction for content principle,» a communicative type of correction which Johnson holds «should assess whether information content has been correctly conveyed» (171). Further on he adds, though, that «The correction for content principle argues that at some stage the student's language production should be judged on its communicative efficacy in relation to a specific task. But the principle does not negate the utility of teacher correction for grammatical accuracy at some other stage ... It may often happen that the student succeeds in getting his message across (in a grammatically imperfect way) to a peer who may share his grammatical imperfections. For this reason teacher correction is also important. In the ultimate analysis he is also 'correcting for content' because grammar expresses content» (173 emphasis is mine).

Omaggio, in her turn, points out that «some type of error correction may be useful in helping learners both to avoid early fossilization and to develop higher levels of competence that will make their interlanguage acceptable to native speakers» (291). The key questions can be stated like this: When should correction and feed-back be provided, what errors should be pinpointed, and how do students react to error correction? Omaggio offers a deep analysis of the answers to these questions as reported in the useful publication Error-Correction Techniques for the Foreign Language Classroom (Walz). I will focus here on some procedures for correcting written work.

There seems to be general agreement among researchers about the fact that correction of every single error on the student's written work is not always very useful to provide corrective feedback. On the one hand, the student may feel discouraged; on the other, by supplying all of the corrections, the teacher may be hindering the learner's progress in building proficiency in writing. We can propose, instead, a type of selective approach and the use of discovery techniques. Lower-level students, who may not be able to find their own errors and correct them, can be given specific clues about the location and correction of their errors, whereas more advanced students can be given a cuing system by means of which their errors are located, but tiley are responsible for finding the solutions. We can use two types of correction techniques: indirect, through the location of errors indicated by a variety of symbols (underlining incorrect spelling, circling inappropriate vocabulary, inserting an arrow for missing words, or placing a question mark next to confusing phrases or structures), and direct (underlining the word and providing a tip, such as «use a past tense,» bracketing a misplaced word or phrase 
and indicating with arrows the proper placement, crossing out an unnecessary word, or providing the correct form or structure).

Celce-Murcia (2) holds that there are more effective and. less effective ways of correcting ESL students when formal accuracy is desirable. In this sense, at least five dimensions should be kept in mind when doing correction. These dimensions can be represented by means of this grid:

Less

Effective

- Teacher lectures, gives rule or explains

- Teacher corrects directly

- Teacher gives indirect, diffused cues on type and location of correction needed

- Teacher conducts mechanical drill of problematic form

- Teacher corrects everything
More

Effective

- Teacher elicits information from class

- Teacher elicits peer or self correction

- Teacher gives focused, specific cues as to what correction is needed and where

- Teacher conducts meaningful practice of problematic form

- Teacher corrects selectively

As for the possibility of assigning a grade to our students' journals, we must keep in mind that the goal is to test expiessive performance skills, which means that complete objectivity is not possible. As Chastain puts it,

Identifying all the linguistic choices a student makes during the writing of a one-page composition and the difficulty level of each in the evaluation of the final product lies beyond the realm of practical qualities. The task is too complex to be reduced to discrete points of linguistic elements. A global, subjective evaluation is more appropriate from the point of view of the skill being rated and more realistic from the point of view of the grader. (511)

We must not forget that the question of evaluating communicative competence is one that each teacher must address depending on his/her own teaching circumstances. We can only focus-and negotiate, an element, I insist, not to be left out-different aspects of student performance as a basis for evaluation, and select a scale for rating that performance. Whatever the rating system we choose, the quality of written work consists of several factors, such as naturalness of expression, variety and appropriateness of vocabulary used, variety and complexity of structures, grammatical correcteness, sentence length and complexity, amount of information conveyed, fluency, etc. Taking these factors as a basis, the teacher can devise a scale composed of different grades, having made clear to and with the students-for ultimately it is for them to judge their own performance-the quality of work each grade represents as far as highquality, good, in need of improvement, and unacceptable work. ${ }^{6}$

It is my opinion that such a procedure, together with the error correction system proposed and the very nature of this method of assessement, allows us to regard journals as a communicative type of assessment: both in form and content, they resemble actual performance necessary in life, they are perceived by students as learning tools, and they create a moderately relaxed atmosphere. 


\section{Conclusion}

Taking the methodological framework proposed by the Communicative Approach to Language Teaching as a basis, I have pointed out the dynamic interdependence of its three components-purpose, methodology and evaluation-and I have focused on evaluation. The highly evaluative nature of our communicative performance-we keep making judgements on the acceptability of the utterances we utter and hear - can be transferred to the evaluation procedure of the curriculum, which means evaluation becomes a negotiated and intersubjective matter which allows us, in its turn, to evaluate the curriculum itself.

Within this new methodological set, self-evaluation emerges as a powerful assessment instrument. Self-assessment can be carried out in different ways, one of these being journals, to which I have devoted the main body of this paper. In addition to fulfilling the traditional function of evaluating the learners' progress in the course of an instructional program, together with the complementary function of evaluating the curriculum, journals have the advantage of involving students in different aspects of their teaching environment, such as the negotiation of the content and the grading scale, if necessary, and sharing responsibility with the teacher as far as class management goes. Journals help to lower students' affective filter, and, above all, they are regarded as a real life performance task. And finally, they provide evidence about the fact that an assessing technique does not necessarily have to be only an evaluation tool, but can also-and should actually always be--perceived by students as a learning tool.

\section{Notes}

1. Journals are a common practice in intensive writing classes and in foreign language classes for both native and non-native speakers of English studying at US universities. Regardless of other purposes journals can be used for, or other approaches to this technique, the way I design them here is directly based on my experience as a Teaching Assistant of Spanish at the University of Illinois, Urbana-Champaign, Fall 1988 and Spring 1989.

2. It may give the impression that in these journals I establish a distinction between an «academic» and a «personal» part, so to speak. Yet it is my opinion that asking students to express their reactions to the class and letting them know that their opinions will have an actual effect in class management has in their minds the power of turning this learning introspection into a «personal» question which merges with their everyday interests.

3. I am using the term «learning» in a generic sense. I am not suscribing here to Krashen and Terrell's distinction between «learning» and «acquisition.»

4. It goes without saying this mutual knowledge is only possible in those classrooms with an operative number of students, something which, unfortunately, is not always the case in the real academic world.

5. The first possibility describes the way I dealt with journals during my American experience. The feedback I provided my students consisted of my opinions about the content of their writings, and some error corrections, which varied according to the level of instruction. However, in the long run I detected in some of my students that sort of «wishy-washy» attitude we referred to before. In my opinion, a self-scoring procedure as suggested here would have 
introduced that «facilitative anxiety» element which would have prevented these students from lowering their guard.

6. As our course objectives will vary according to the Ievel of knowledge, the same type of grading scale can be used for different levels of proficiency.

\section{Works Cited}

Bachman, L. F. Fundamental Considerations in Language Testing. Urbana-Champaign: U of Illinois P, 1988.

Brecn, M. P. and C. N. Candlin. «The Essentials of a Communicative Curriculum in Language Teaching.» Applied Linguistics 2 (1979): 89-111.

Brown, H. D. Principles of Language Learning and Teaching. Englcwood Hills, N. J.: PrenticcHall, 1987.

Celce-Murcia, M. «Making Informed Decisions About the Role of Grammar in Language Teaching.» TESOL Newsletter 19 (1985): 1-4.

Chastain, Kenneth D. «Evaluating Expressive Objectives.» Readings on English as a Second Language. Ed. Kenneth Croft. Cambridge, Massachusetts: Winthrop, 1980, 507-17.

Clark, John L. "Classroom Assessment In A Communicative Approach.» The British Journal of Language Teaching 1 (1987): 9-19.

Johnson, K. «Five Principles in a 'Communicative' Exercise Type.» Communicative Syllabus Design and Methodology. Ed. K. Johnson. Oxford: Pergamon, 1982. 55-69.

Krashen, S. D. and T. D. Tcrrell. The Natural Approach: Language Acquisition in the Classroom. New York: Pergamon; San Francisco: Alemany, 1983.

Lee, Barbara. "Classroom-Based Assessment-Why and How?» The British Journal of Language Teaching 2 (1989): 73-76.

Markee, Numa. «The Diffusion of Communicative Innovations and Classroom Culture: An Ethnographic Study.» Paper presented at the 24th Annual TESOL Convention, San Francisco, CA, March 1989.

Oller, John. «Language Testing Today.» Readings on English as a Second Language. Ed. Kenneth Croft. 481-91.

Omaggio, A. Teaching Language in Context. Boston: Heinle and Heinle, 1986.

Oscarson, Mats. «Self-Assessment of Language Proficiency: Rationale and Applications.» Language Testing 1 (1989): 1-13.

Rivas, Rosa. «John Katzman: entrena a estudiantes de todo el mundo para superar las trampas de los tests.» Suplemento de Educación. El País 2 de octubre de 1990: 8.

Shohamy, E. «Affective Considerations in Language Testing.» Modern Language Journal 66 (1982): 13-17.

Walz, Joel. Language in Education: Theory and Practice Series. No. 50. Washington, D. C.: Center for Applied Linguistics, 1982.

Waters, Alan. «Participatory Course Evaluation.» English for Specific Purposes 1 (1987): 3-12. 